\title{
Comparative Advertising
}

\author{
Simon P. Anderson*and Régis Renault ${ }^{\dagger}$ \\ This version October 2006. \\ PRELIMINARY: COMMENTS WELCOME
}

\begin{abstract}
Consumer information on products affects competition and profits. We analyze firms' decisions to impart product information through advertising: comparative advertising also allows them to impart information about rivals' products. If firms sell products of similar qualities, both want to advertise detailed product information that enables consumers to determine their matches: there is no role for comparative advertising. If qualities are sufficiently dissimilar, the high-quality one will not want to disclose match information. If legal, the low-quality firm rival would like to advertise match information about its rival. Such "comparative" advertising may have a detrimental impact on welfare by leading more consumers to consume the low quality product: this effect can dominate the benefits from improved consumer information and reduce social welfare if qualities are different enough.

Keywords: comparative advertising, information, product differentiation, quality. JEL Classification: D42 L15 M37

Acknowledgement 1 We gratefully acknowledge travel funding from the CNRS and NSF under grants INT-9815703 and GA10273, and research funding under grant SES0137001. We thank Öykü Ünal and Joshua Gans for comments, along with various seminar participants (Toulouse I, ECARES-ULB, CORE-UCL, Boston University, Roy seminar in Paris, St. Andrews University, Pompeu-Fabreu, Melbourne Business School, University of Southern California, Claremont-McKenna, Virginia) and conference attendees (CESIfo 5th Area conference on Applied Micro in Munich and EARIE in Oporto). We thank IDEI (University of Toulouse I) and the University of Montpellier and Melbourne Business School for their hospitality.
\end{abstract}

*Department of Economics, University of Virginia, PO Box 400182, Charlottesville VA 22904-4128, USA. sa9w@virginia.edu

${ }^{\dagger}$ ThEMA, Université de Cergy-Pontoise, 33 Bd. du Port, 95011, Cergy Cedex, FRANCE and Institut Universitaire de France. regis.renault@u-cergy.fr 


\section{Introduction}

Until the late 1990s, mentioning a competitor's brand in an ad was illegal in many EU countries. This situation was ended by a 1997 EU directive that made "comparative advertising" legal subject to the restriction that it should not be misleading. This brought the European approach closer to that of the FTC in the US. In other countries, comparative advertising remains illegal, or little used (see Donthu, 1998, for a cross-country comparison). The rationale for a favorable attitude towards "comparative advertising" on the part of competition authorities is that it improves the consumers' information about available products and prices (see Barigozzi and Peitz, 2005, for details and a wealth of examples and discussion). This raises a number of questions for the economic analysis of informative advertising. What is the scope of a practice that involves disclosing information that the product's supplier would choose not to reveal? Is the benefit to consumers from improved information mitigated by a welfare loss for competitors who are (presumably) hurt by comparative advertising about their products? Are consumers hurt by higher prices because product differentiation rises due to comparative advertising about product attributes?

Here we consider a game between rival firms and their incentives to provide information. Consumers do not know the characteristics of a firm's product unless they are revealed through advertising, although consumers have (correct) priors about their evaluations. Firms are fully aware of each other's product attributes. If comparative advertising is not permitted, then firms can only inform consumers about their own goods. If comparative advertising is permitted, the other firm can also inform consumers about product attributes that its rival might not wish to communicate. The analysis also treats the welfare economics of comparative advertising.

Evaluating the impact of comparative advertising on market outcome requires identifying situations where the possibility of comparative advertising changes the information available 
to consumers. In other words, there must be some information that firms would not disclose if restricted to direct advertising, and that will be brought out if comparative advertising is allowed. In much of the literature on informative advertising, sending ads is costly and it is the cost of advertising that limits the information transmission by firms (see the seminal papers of Butters, 1977, Grossman and Shapiro, 1984, and the review coverage in Bagwell, 2006). Anderson and Renault (2006) explore the possibility that a monopoly firm might choose to provide limited information about its product attributes even if advertising has no cost. This result is a starting point for the present paper because it identifies situations where a firm is hurt by information disclosure about its own product, so that there might be some incentives for competitors to provide that information through comparative ads. The paper is novel in several dimensions. First, it contributes to the economics of asymmetric oligopolistic competition, indicating how quality-cost advantages feed into equilibrium prices and sales. Second, it provides results on the impact of increased product information on market outcomes: while more information tends to increase profits, and welfare when qualities are similar, welfare can be harmed with more information due to price distortions when qualities are quite different. Third, it provides some predictions on when comparative advertising might be used - by smaller firms with cost or quality disadvantages.

There is curiously little economics literature on comparative advertising, although in marketing there is quite a lot of documentation of the phenomenon, and discussion of its effectiveness (see Grewal et al., 1997, for a comprehensive survey). ${ }^{1}$ Barigozzi and Peitz (2005) give a survey and some background modeling of alternative approaches. Barigozzi, Garella, and Peitz (2006) take a signalling approach. An entrant with uncertain quality confronts an incumbent whose quality is known. The entrant chooses between "generic" advertising, which is standard money burning to signal quality (as in Nelson, 1974), and

\footnotetext{
${ }^{1} \mathrm{~A}$ recent paper by Thompson and Hamilton (2006) shows subjects four different ads, with different comparative and analytical cues and judges ad effectiveness by surveying participants' impressions.
} 
"comparative" advertising, which involves a claim comparing the two firms' qualities. Firms may have favorable or unfavorable information about the entrant's quality but do not observe it perfectly. If comparative advertising is used, the incumbent may litigate in the hope of obtaining damages if the court, which may observe quality perfectly, finds that it is low. Comparative advertising may credibly signal favorable information about entrant quality because a firm holding such information expects that it is unlikely that a court will find that its quality is low. Aluf and Shy (2001) model comparative advertising (using a Hotellingtype model of product differentiation) as shifting the transport cost to the rival's product. While this is an interesting angle in its own right, the modeling approach does not capture the informative aspect of comparison advertising and is not micro-founded in information revelation. Instead, it seems more like a model of (negative) "persuasive" advertising.

We consider the disclosure of horizontally differentiated attributes that are valued differently by different consumers assuming that product qualities are known. If product qualities are sufficiently different, the equilibrium to the disclosure game has only the firm with the low quality disclosing horizontal attributes and the high one not. If comparative advertising is allowed, then the low-quality firm will disclose the horizontal attributes of both products (and so it is truly comparative).

Section 2 gives useful general results for Bertrand duopoly with product differentiation. We outline the model in Section 3, describe demand under different degrees of product information, and find the corresponding equilibrium prices. The outcomes are compared in Section 4. The equilibrium information disclosure is determined in Section 5, and Section 6 shows how the results also cover two alternative formulations of the basic model (search goods and quality revelation). Section 7 concludes. The longer proofs are collected in the Appendix. 


\section{Some preliminary results}

We first give some results for duopoly pricing that are important to the analysis that follows. Since they are used quite extensively, we give them first. The demand curves considered below will satisfy the properties used in these results. The results pertain quite generally to differentiated product Bertrand duopoly with covered markets.

Consider a duopoly where firms 0 and 1 set prices $p_{0}$ and $p_{1}$. Define $\Delta$ as Firm 1 's net quality advantage, $\Delta=p_{0}-p_{1}+Q$, where $Q \in \mathbb{R}$ may be understood as a Firm 1's gross quality advantage. Demand for Firm $i$ 's product is given by $D_{i}(\Delta), i=0,1$, where $D_{1}$ is an increasing function taking values in $[0,1]$ defined on $\mathbb{R}$. Further assume that $D_{0}=1-D_{1}$, which may be understood as a covered market assumption: if heterogenous consumers have unit demands, each consumer must buy either product (and total demand is normalized to 1). Production costs are assumed to be zero (though the model may be reinterpreted to allow for positive and different production costs as explained below).

Assume that $D_{1}(0)=D_{0}(0)=\frac{1}{2}$ so that, if $Q=0$ and firms charge the same price, they share demand equally. Thus, $Q=0$ may be viewed as a symmetric case, whereas when $Q \neq 0$, one firm has a competitive advantage over the other one in the sense that it may charge a larger price than its competitor and still serve at least half the market (Firm 1 having the competitive advantage if $Q>0$ and Firm 0 having the competitive advantage when $Q<0$ ). This competitive advantage is presented for the exposition as a quality difference, but could also be (and is formally equivalent to) a marginal production cost difference (marginal costs being constant). To see this, simply reinterpret $p_{i}$ as a mark-up over marginal cost. More generally the firm with the competitive advantage is the one that has the larger difference between its quality and its marginal cost. ${ }^{2}$

\footnotetext{
${ }^{2}$ To see this, let $c_{0}$ and $c_{1}$ denote firms' (constant) marginal costs, and define $m_{i}=p_{i}-c_{i}$ as Firm $i$ 's mark-up. Redefine $Q=\left(q_{1}-c_{1}\right)-\left(q_{0}-c_{0}\right)$ and set $\Delta=m_{0}-m_{1}+Q$. Then Firm 1's profit is $\pi_{1}=m_{1} D_{1}(\Delta)$ and now view firms as choosing their mark-ups. Hence the formal analysis is unaffected: note that $\Delta=q_{1}-p_{1}-\left(q_{0}-p_{0}\right)$ so that the demand functions are just as before. The advantaged firm is now
} 
We first establish a general result characterizing Firm 1's equilibrium net competitive advantage, $\Delta$, and how it relates to the gross competitive advantage $Q$.

Lemma 1 Assume $D_{0}=1-D_{1}$, and $D_{1}(\Delta)=\frac{1}{2}$ if and only if $\Delta=0$. Then in any pure strategy Nash equilibrium of the game where prices are chosen simultaneously, $\Delta$ has the sign of $Q$ and

$$
0 \leq|\Delta| \leq|Q|
$$

with equality only if $Q=0$.

Lemma 1 is proved in the Appendix using revealed preference arguments. The next result follows directly.

Corollary 1 If $Q=0$, then $p_{0}=p_{1}$ and $D_{0}=D_{1}$ in equilibrium.

If $Q>0$, then $p_{0}<p_{1}$ and $D_{0}<D_{1}$ in equilibrium.

This states that whichever firm has a competitive advantage retains that advantage in equilibrium and thus has higher demand ( $\Delta$ has the same sign as $Q$ ) but this advantage is somewhat mitigated because the weaker firm charges a lower price $(|\Delta|<|Q|$ if $Q \neq 0)$. It also states that in the symmetric case where $Q=0$, firms must share the market equally. The present results extend those of Anderson and de Palma (2001), who show such properties hold with the multinomial logit demand model (and $n \geq 2$ competing firms).

We now put some additional structure on demand in order to tighten the characterization of equilibrium pricing.

Assumption 1 There exist two, possibly infinite, real numbers $\Delta_{\ell}$ and $\Delta_{u}$ such that $D_{1}(\Delta)=$ 0 if and only if $\Delta \leq \Delta_{\ell}$ and $D_{1}(\Delta)=1$ if and only if $\Delta \geq \Delta_{u}$. Furthermore, $D_{1}$ is differentiable on $\left[\Delta_{\ell}, \Delta_{u}\right]$ and $D_{1}^{\prime}>0$ on $\left(\Delta_{\ell}, \Delta_{u}\right)$.

seen as the one with the higher quality-cost, and all results that follow can be appropriately re-interpreted. 
Since $D_{1}$ is increasing and $D_{1}(0)=\frac{1}{2}$, we must have $\Delta_{\ell}<0<\Delta_{u}$. The differentiability assumption does not rule out a non-differentiable point of $D_{1}$ at either bound but merely guarantees that there is a right derivative at $\Delta_{\ell}$ and a left derivative at $\Delta_{u}$. Henceforth we use $D_{1}^{\prime}\left(\Delta_{\ell}\right)$ and $D_{1}^{\prime}\left(\Delta_{u}\right)$ to denote inside derivatives at these points. As we will see below, differentiability of $D_{1}$ at $\Delta_{\ell}$ or $\Delta_{u}$ has important implications for the market outcome.

A key property of the demand derivatives is that $D_{0}^{\prime}(\Delta)=-D_{1}^{\prime}(\Delta)$. Since $\Delta=p_{0}-p_{1}+Q$ and $D_{0}=1-D_{1}$, the derivatives of each firm's demands with respect to the firm's own price are equal and given by $-D_{1}^{\prime}(\Delta)$.

For $\Delta \in\left(\Delta_{\ell}, \Delta_{u}\right)$, equilibrium prices must satisfy standard first-order conditions setting profit derivatives to zero. Thus prices may be written as

$$
p_{1}=\frac{D_{1}(\Delta)}{D_{1}^{\prime}(\Delta)} \quad \text { and } \quad p_{0}=\frac{D_{0}(\Delta)}{-D_{0}^{\prime}(\Delta)}=\frac{1-D_{1}(\Delta)}{D_{1}^{\prime}(\Delta)}
$$

From equation (1) we derive a simple fixed point condition that fully characterizes $\Delta$ as a function of $Q .{ }^{3}$ Differencing the price expressions in (1) we have Firm 0's price premium as

$$
g(\Delta) \equiv \frac{1-2 D_{1}(\Delta)}{D_{1}^{\prime}(\Delta)}
$$

recalling that $\Delta=p_{0}-p_{1}+Q$, we then have

$$
Q=\Delta-g(\Delta)
$$

In order for equations (1) and (3) to be relevant, it is necessary that in equilibrium $\Delta$ falls strictly between $\Delta_{\ell}$ and $\Delta_{u}$. As we prove in the Appendix, this will be the case for all $Q$, if $D_{1}$ is differentiable at $\Delta_{\ell}$ and $\Delta_{u}$, which means if the inside derivatives are zero there.

\footnotetext{
${ }^{3}$ Equation (1) also yields a quick proof (given differentiability) for Lemma 1 and its Corollary. When both demands are positive, the first-order conditions are $p_{i}=\frac{-D_{i}(\Delta)}{D_{i}^{\prime}(\Delta)}$ (as per (1)). Since in any equilibrium, $D_{0}^{\prime}(\Delta)=-D_{1}^{\prime}(\Delta)$, then higher prices are associated to higher demands. But this means that, since we have $D_{0}(0)=1 / 2$, the firm with the lower demand has a higher net quality. That is, $p_{0}<p_{1}$ holds if and only if $D_{0}<D_{1}$ and if and only if $\Delta>0$. Taking the first and last inequalities, this can be only true if $q_{1}>q_{0}(Q>0)$. The equality results follow immediately along similar lines. This result means intuitively that a quality (or cost) advantage is reflected in a higher mark-up and yet higher demand since the quality advantage is only partially offset with a higher price.
} 
Lemma 2 Under Assumption 1, in any pure strategy Nash equilibrium, $\Delta \in\left[\Delta_{\ell}, \Delta_{u}\right]$. Furthermore, if for some $k \in\{\ell, u\}, D_{1}$ is differentiable at $\Delta_{k}$, then $\Delta \neq \Delta_{k}$ for all $Q \in \mathbb{R}$.

The above results characterize the equilibrium provided that it exists. Further regularity conditions must be imposed on $D_{1}$ to guarantee existence as well as uniqueness of an equilibrium. We thus assume the following.

Assumption $2 D_{1}$ and $D_{0}$ are strictly log-concave on $\left[\Delta_{\ell}, \Delta_{u}\right]$.

This means that $\ln D_{i}$ is strictly concave, so $D_{i}^{\prime} / D_{i}$ is strictly decreasing.

Proposition 1 Under Assumptions 1 and 2, the game in which firms choose prices simultaneously has a unique pure strategy Nash equilibrium, such that $p_{0}, p_{1}$, and $\Delta$ satisfy

1. If $\Delta_{\ell}-\frac{1}{D_{1}^{\prime}\left(\Delta_{\ell}\right)}<Q<\Delta_{u}+\frac{1}{D_{1}^{\prime}\left(\Delta_{u}\right)}$, then $\Delta$ is given by (3) and $p_{0}$ and $p_{1}$ are given by (1). Furthermore $\Delta$ is strictly increasing in $Q$ with $\frac{d \Delta}{d Q}<1$.

2. If $Q \leq \Delta_{\ell}-\frac{1}{D_{1}^{\prime}\left(\Delta_{\ell}\right)}$, then $\Delta=\Delta_{\ell}, p_{1}=0$ and $p_{0}=\Delta_{\ell}-Q$.

3. If $Q \geq \Delta_{u}+\frac{1}{D_{1}^{\prime}\left(\Delta_{u}\right)}$, then $\Delta=\Delta_{u}, p_{0}=0$ and $p_{1}=Q-\Delta_{u}$.

Thus, whether or not equilibrium entails positive demands for both firms for all $Q$ boils down to whether or not the demand derivative is zero at the point where one demand becomes zero. To see this, suppose there is a zero derivative at (a finite) $\Delta_{u}$ (of course, the argument also holds for an infinite $\Delta_{u}$ but the finite case is more striking and bears better juxtaposition with the case of a finite derivative). Then even for very high $Q$ it will not be worth Firm 1 pricing out Firm 0 from the market when $p_{0}=0$, because the mass of last customers to get on board becomes vanishingly small at a high price (approaching $Q-\Delta_{u}$ ) and loses revenue on the existing consumer base. With a finite derivative, the trade-off becomes attractive at a high enough quality. 
Corollary 2 Under Assumptions 1 and 2, whenever Firm 1's demand is strictly positive, its profit is strictly increasing in $Q$ and whenever Firm 0's demand is strictly positive, its profit is strictly decreasing in $Q$.

Proof. From Proposition 1, the equilibrium $\Delta$ is increasing in $Q$ and strictly increasing in case 1. Since $D_{1}$ is increasing in $\Delta, D_{1}$ is increasing in $Q$ and $D_{0}$ is decreasing in $Q$.

To complete the proof it suffices to show that $p_{1}$ is strictly increasing in $Q$ whenever $D_{1}>0$ and $p_{0}$ is strictly decreasing in $Q$ whenever $D_{0}>0$. This is immediate in cases 2 and 3. In case 1 prices are given by Equation (1). Since $D_{1}$ and $D_{0}$ are assumed to be strictly log-concave, $p_{1}$ is strictly increasing in $\Delta$ and $p_{0}$ is strictly decreasing in $\Delta$ which proves the result since $\Delta$ is strictly increasing in $Q$ in case 1 .

\section{The model}

Consumers are interested in buying one unit of one of two goods, which are sold by separate firms. The intrinsic benefit of the product class is large enough that all consumers buy one of the two products. Each product's specification is summarized by consumer valuations, which are assumed independently, identically, and symmetrically distributed around zero with density $f($.$) , distribution function F($.$) , and support [-b, b]$. Hence $f(x)=f(-x)$ and $F(0)=1 / 2$. We write consumer utility as

$$
u_{i}=q_{i}-p_{i}+r_{i}, \quad i=1,2,
$$

where $q_{i}$ is product $i$ 's quality, $p_{i}$ its price, and $r_{i}$ is the consumer's match value. We consider an experience good so purchases depend only on expectations of match values. ${ }^{4}$

\footnotetext{
${ }^{4}$ In Section 6 we show that the basic results hold in a variant on the model in which we allow consumers to acquire the missing information through search in a setting that is similar to that used in Wolinsky (1986) and Anderson and Renault (1999) and (2000).
} 
Consumers observe prices (for example, in the store where purchases are made). They also know qualities: this can either be viewed as a direct assumption or else it follows from the analysis of Section 6 that if qualities are unknown to consumers, firms will reveal them in equilibrium (this is an extension of the basic "persuasion game" of Milgrom, 1981). However, absent advertising, consumers do not know their match valuations. Firms are able to advertise their own product specification if they so wish. Such "positive" advertising will allow consumers to know their realizations of $r_{i}$. If firms are allowed to advertise rival product specifications, either they only do that ("negative advertising") and consumers know their realizations of $r_{j}$, or else a firm can advertise both product specifications, so consumers then know both $r_{i}$ and $r_{j}$, a situation we refer to as "comparative advertising." Even though there is nothing untruthful in comparative or negative advertising, this may be information that Firm $i$ may choose not to reveal on its own. If there is no information on Firm $i$ 's product specification (and hence the value of $r_{i}$ ), consumers must form expectations of their benefits from buying from Firm $i$. Consumers cannot otherwise acquire any information through search. An alternative phrasing of the model with a search good instead of an experience good is shown in Section 6 to give rise to an equivalent formulation as long as the search cost is high enough.

We next describe demand under the alternative consumer information states that might arise from advertising.

\subsection{No information}

If neither firm advertises, the consumers know only the expected value from purchasing from either of them. Since the mean match value is zero (by the assumption of symmetry of $f$ ), expected utility is

$$
u_{i}=q_{i}-p_{i}
$$


Products are ex-ante homogenous except for the quality differential. Firm 1's demand is then zero if $\Delta<0$, and one if $\Delta>0$. If $\Delta=0$, we invoke a standard tie-breaking rule that assigns all demand to Firm 1: since we assume $Q \geq 0$, this corresponds to "efficient rationing" when $Q>0$, and has no bite when $Q=0$.

The price equilibrium under no information is quite straightforward. It follows from a standard Bertrand equilibrium argument that the low quality firm sets a zero price in equilibrium and the high-quality one serves the whole market at a price of $Q .{ }^{5}$ Since the market size is normalized to unity, $Q$ is also Firm 1's equilibrium profit.

\subsection{One-sided information}

Here we characterize the demand (indicated with a bar) that ensues when the information advertised concerns only one of the products (for example, only one firm advertises its product specification).

Suppose that Firm 0's match is known. Then, since the expected match value with Firm 1 is zero, the relevant utilities are

$$
u_{0}=q_{0}-p_{0}+r_{0}
$$

and

$$
u_{1}=q_{1}-p_{1}
$$

These expressions give rise to a demand facing Firm 1 given by $\operatorname{Pr}\left(u_{0}<u_{1}\right)$ or

$$
\bar{D}_{1}=\operatorname{Pr}\left(r_{0}<\Delta\right)=F(\Delta)
$$

Since the support of $r_{0}$, the random variable underlying $F($.$) , is [-b, b]$ we have here that

\footnotetext{
${ }^{5}$ Without further restriction, any price premium of $Q$ with the price of the high quality firm between 0 and $Q$, is an equilibrium outcome to this game. Anderson and de Palma (1987) show that the equilibrium we select is the unique limit of equilibria in a horizontally differentiated market, as product heterogeneity goes to zero. This rules out equilibria where the low-quality firm (which makes no sales) prices below marginal cost.
} 
$\bar{D}_{1}(\Delta)=1$ for $\Delta \geq \Delta_{u}=b$, and $\bar{D}_{1}(\Delta)=0$ for $\Delta \leq \Delta_{l}=-b$, and Assumptions 1 and 2 are satisfied for this demand. Hence Proposition 1 holds.

We now argue the allocation of consumers to firms in such a situation is independent of which firm's match values are known (so the result is the same). Indeed, if Firm 1's match is known and Firm 0's match is unknown, the utilities relevant to choices are $u_{0}=q_{0}-p_{0}$ and $u_{1}=q_{1}-p_{1}+r_{1}$. The demand facing Firm 1 is then $\bar{D}_{1}=1-F(-\Delta)$. However, this demand expression is the same as (5) since symmetry of $f$ implies $F(x)=1-F(-x)$. In summary:

Lemma 3 If advertising is one-sided, a firm's demand does not depend on which firm's match values are known.

Thus it makes no difference which firm's matches are advertised (given only one firm's are). This means there is no systematic bias in the model to favor negative or positive advertising.

Under one-sided information, from the analysis of Section 2, whether or not one firm is excluded from the market in equilibrium depends on whether $Q$ is high enough and whether the derivative of demand is positive or zero at the upper bound. Since that derivative is simply $f(b)$ (where $b=\Delta_{u}$ in the earlier notation), then we immediately have the following result as a corollary to Lemma 2 and Proposition 1.

Lemma 4 Suppose information is one-sided. Then equilibrium demands are both positive regardless of $Q$ if $f(b)=0$. If $f(b)>0$, then for $Q \geq b+\frac{1}{f(b)}$, Firm 1 serves the whole market in equilibrium and sets a price $p_{1}=Q-b$; for lower $Q$ the market is shared and $p_{0}$, $p_{1}$, and $\Delta$ are given by equations (1) and (3).

Proof. The result is a direct corollary of Proposition 1. 
Note that the case $f(b)=0$ covers the case when the support of match values is the extended real line. With a finite support and $f(b)>0$, the quality-advantaged firm prices so as to just retain the individual enjoying the highest regard for Firm 0, which is the individual who has a match $r_{0}=b$. This compares to the mean value of 0 for Firm $1 .^{6}$

\subsection{Full information}

Consumers know exactly their match values with both products if they have been advertised. A consumer with full information purchases product 1 if and only if

$$
q_{1}-p_{1}+r_{1} \geq q_{0}-p_{0}+r_{0}
$$

or equivalently

$$
r_{1}+\Delta \geq r_{0}
$$

The probability a consumer with a given realization of $r_{1}$ buys from Firm 1 is $F\left(r_{1}+\Delta\right)$. Integrating over all possible values of $r_{1}$ gives the demand for Firm 1 as

$$
\widetilde{D}_{1}(\Delta)=\int_{-b}^{b} F\left(r_{1}+\Delta\right) f\left(r_{1}\right) d r_{1}
$$

and $\widetilde{D}_{0}(\Delta)=1-\widetilde{D}_{1}(\Delta)$, where full-information demands are characterized with a tilde. ${ }^{7}$

The range of values of $\Delta$ for which $\widetilde{D}_{1}(\Delta)$ is strictly between 0 and 1 is from $\Delta_{l}=-2 b$ to $\Delta_{u}=2 b$, and Assumptions 1 and 2 are satisfied for this demand. These bounds arise because these are the values for which at least some value of $F\left(r_{1}+\Delta\right)$ in (6) is neither zero or one. For example, if $\Delta=2 b$, even the consumer who least likes product 1 and most

\footnotetext{
${ }^{6}$ Equivalently, as per Lemma 3, if Firm 1 reveals its match information while Firm 0 does not, 1 must price so that the consumer least enamoured of it (holding $r_{1}=-b$ ) nonetheless buys against an expected value of 0 with Firm 0.

${ }^{7}$ By Lemma 1 we can concentrate on the case $\Delta \geq 0$. Then (6) becomes $\tilde{D}_{1}(\Delta)=$ $\int_{-b}^{b-\Delta} F\left(r_{1}+\Delta\right) f\left(r_{1}\right) d r_{1}+1-F(b-\Delta)$. Demand can be visualized as the area of the unit square of consumer valuations accorded to each firm. The division line (indifferent consumer type) satisfies $r_{1}=r_{0}-\tilde{\Delta}$, which is a diagonal line. If $\tilde{\Delta}>0$, Firm 1 attracts all those consumers for whom $r_{0}<\tilde{\Delta}$ irrespective of their valuation of $r_{1}$ : hence the final term in the demand function.
} 
likes product zero (that is, $\left.\left(r_{0}, r_{1}\right)=(b,-b)\right)$ will just switch to buying product 1 because its net quality advantage is so high. Nonetheless, even though the demand function itself has a bound above which it is one (for $b$ finite), we shall see below (using Proposition 1), that in equilibrium demand will always be below one.

We first use Lemma 1 above to characterize the equilibrium outcome under perfect information that will prevail if information about both firms' products are disclosed through advertising.

Although this demand function has the whole market served by Firm 1 if $\Delta \geq 2 b$, this never happens in equilibrium. This property is a direct corollary of Lemma 2 and Proposition 1. Since for $\Delta>0$ we can write $(6)$ as $\widetilde{D}_{1}(\Delta)=\int_{-b}^{b-\Delta} F\left(r_{1}+\Delta\right) f\left(r_{1}\right) d r_{1}+1-F(b-\Delta)$, then $\widetilde{D}_{1}^{\prime}(\Delta)=\int_{-b}^{b-\Delta} f\left(r_{1}+\Delta\right) f\left(r_{1}\right) d r_{1}$ and this expression is zero for $\Delta=2 b$. This puts us always in Case 1 of Proposition 1.

Lemma 5 Suppose information is perfect. Then equilibrium demands are positive regardless of $Q$. Equivalently, the equilibrium $\Delta$ is always below $2 b$ and $p_{0}, p_{1}$, and $\Delta$ are given by equations (1) and (3).

Proof. This corresponds to Case 1 in Proposition 1, namely that $\Delta<\Delta_{u}$ in equilibrium.

Even though Firm 1 has the ability to price 0 out of the market, it never exercises the option because the marginal gain in consumers is so small even when the stakes (the price) are very large.

\subsection{Comparing demands}

We now establish a result which will be used later for the asymmetric cases, and helps build intuition for the results. The expressions compared are demands under full and one-sided 
information (see (5) and (6)). ${ }^{8}$

Proposition 2 Let $\Delta$ be some real number. We have

$$
\widetilde{D}_{1}(\Delta)=\int_{-b}^{b} F\left(r_{1}+\Delta\right) f\left(r_{1}\right) d r_{1} \leq F(\Delta)=\bar{D}_{1}(\Delta)
$$

if and only if $\Delta \geq 0$, with equality if and only if $\Delta=0$.

This result is suggestive of forces at play in the equilibrium disclosure analysis, but it is not conclusive because the comparison of demands treats $\Delta$ as fixed rather than determined at its equilibrium value in the information state. The Proposition already suggests that Firm 0 is better off when information is full because it has higher demand for given $\Delta>0$ (i.e., $\left.\widetilde{D}_{0}(\Delta)>\bar{D}_{0}(\Delta)\right)$. However, it is less clear whether the equilibrium $\Delta$ also favors it under full information, but one might suspect that it could support a higher price insofar as full information (loosely) means greater perceived product differentiation. Conversely though, Firm 1 might be expected to be reticent to reveal information because of the first effect: a less attractive demand for given $\Delta$.

For $\Delta=Q$, Proposition 2 provides some insight into the nature of the inefficiency when information is only one-sided. This corresponds to first-best pricing (where prices are equal) and full information then yields the first-best allocation. If only one product is known there is some welfare loss because a consumer may end up choosing the wrong product and Proposition 2 indicates that this inappropriate matching biases demand in favor of the high quality product. This is to be contrasted with the impact of equilibrium pricing, which distorts the allocation of consumers in favor of the low quality product, which is cheaper whether information is full or one-sided. Which informational state yields the higher social

\footnotetext{
${ }^{8}$ This inequality is related to Jensen's inequality. We compare the expected value of some functional transformation of a random variable with the value of that function evaluated at the expected value of the random variable; Jensen's inequality compares these quantities under a convexity assumption on the functional whereas we consider a functional that is first convex and then concave. For the uniform distribution, $F(r+\Delta)$ is peicewise linear and a quick proof of the result may be obtained by applying Jensen's inequality.
} 
surplus depends on the interaction of these two countervailing inefficiencies. We therefore turn to comparing the price sub-games.

\section{Equilibrium pricing under different information states}

We assume that the match density function, $f$, is log-concave. Using arguments from Caplin and Nalebuff (1991), this guarantees that Assumption 2 holds so that existence and uniqueness under one-sided or full information follows from Proposition 1.

\subsection{Equal qualities and information}

We first compare equilibrium prices under symmetry of qualities $\left(q_{0}=q_{1}\right)$. If there is no information, products are viewed as perfect substitutes and a standard Bertrand argument gives them both equal to marginal cost, which we recall is zero.

With one-sided information, demand for Firm 1 is given by (5)) which, for $Q=0$ yields $\bar{D}_{1}=F\left(p_{0}-p_{1}\right)$. Thus demand for Firm 0 is $\bar{D}_{0}=1-\bar{D}_{1}=1-F\left(p_{0}-p_{1}\right)$. Using Lemma $1, \Delta=0$; by Proposition 1 , prices are equal (to $\frac{1}{2 \bar{D}^{\prime}(0)}$ ) and given by

$$
\bar{p}=\frac{1}{2 f(0)} \text {. }
$$

With full information, a consumer holding a value $r_{1}$ for product 1 (and $r_{0}$ for product 0 ) prefers 1 with probability $F\left(p_{0}-p_{1}+r_{1}\right)$. Integrating up over all possible values of $r_{1}$ gives $\widetilde{D}_{1}=\int_{-b}^{b} F\left(p_{0}-p_{1}+r_{1}\right) f\left(r_{1}\right) d r_{1}$ (see also (6)). Again from Lemma 2 and Proposition 1 , both prices are equal to $\frac{1}{2 \tilde{D}^{\prime}(0)}$, or

$$
\widetilde{p}=\frac{1}{2 \int_{-b}^{b} f^{2}(r) d r} .
$$

These prices are compared below.

Proposition 3 If $q_{0}=q_{1}$, then equilibrium prices are higher under full information than under one-sided information than under no information. The uniform density is a limit case for which prices are the same for full and one-sided information. 
Proof. Since $f($.$) is symmetric with maximum at r=0$, then

$$
\int_{-b}^{b} f^{2}(r) d r \leq f(0) \int_{-b}^{b} f(r) d r=f(0)
$$

or, from $(7)$ and $(8), \bar{p} \leq \widetilde{p}$. Equality is only attained with a uniform density, so then prices are equal. Otherwise, we have $\bar{p}<\widetilde{p}$. Since demand is split 50-50, profits are also higher (unless $f$ is uniform) under full information. Both prices exceed the zero price under no information.

With equal qualities, profits are simply equal to half the equilibrium prices. This makes the case that more product information is better for firms (see also Meurer and Stahl, 1994). Full match information (again under equal qualities) is also the information state that gives the highest total welfare. This is because there is no allocation distortion due to unequal prices, and full information enables consumers to reach the first-best solution that each consumer buys her highest match.

The symmetric quality case underscores the product differentiation advantage imparted by full information over limited information. However, the result that a higher degree of product differentiation delivers higher equilibrium prices may have a downside in an extended model. Higher prices may make consumers worse off. It may also even lead to welfare losses if the model is broadened to allow for non-purchase. This is one potential strike against the benefits of informative advertising generally (and not just comparative advertising.)

In conclusion, a symmetric setting does not deliver a distinctive role for comparative advertising. Nor does it enable much useful welfare debate about the welfare benefits of comparative advertising. For that, we turn to the case of quite different qualities.

\subsection{Asymmetric qualities and information}

When qualities are different there are different incentives to firms to reveal information. 
Proposition 4 Let $b$ be finite with $f(b)>0$. Then for $Q$ large enough, no information gives a higher profit level for Firm 1 than one-sided information.

Proof. In the case of one-sided information, for $Q$ large enough we have Firm 1 serving the whole market in the equilibrium to the price sub-game (by Lemma 4). Under no information, Firm 1 also serves the whole market. So it remains to compare prices across information structures. In both cases, Firm 0 sets a price of 0 . Under no information, Firm 1 's price is simply its quality advantage, $Q$. With one-sided information, its price guarantees all consumers prefer it, and so $p_{1}=Q-b$, which is clearly smaller.

This Proposition highlights the possibility that information withholding may benefit firms. The property extends to other information states.

Proposition 5 Let $b$ be finite with $f(b)>0$. Then for $Q$ large enough, one-sided information gives a higher profit level for Firm 1 and a lower profit level for Firm 0 than full information.

Proof. Under one-sided information, Firm 1's price is $Q-b$ for $Q$ large enough (see Lemma 4), and it serves all consumers. Under full information, its price satisfies $\frac{\widetilde{D}_{1}(\Delta)}{\widetilde{D}_{1}^{\prime}(\Delta)}$ with a $\Delta$ that satisfies $\Delta=Q-g(\Delta)$ (see (3)), and it serves less than all consumers. For $Q$ large enough, the appropriate value of $\Delta$ tends to $b$ (from below). Therefore, it suffices for full information to give lower profit that $Q-b \geq \frac{\widetilde{D}_{1}(\Delta)}{\widetilde{D}_{1}^{\prime}(\Delta)}$ as $\Delta$ approaches $b$ along the appropriate path (i.e., given that $\Delta=Q-g(\Delta)$ ). Since both prices tend to infinity, consider their derivatives with respect to $Q$ as $Q$ gets large, and the one with the greater derivative dominates. Thus we wish to show that $1 \geq \lim _{Q \rightarrow \infty} \frac{\partial}{\partial Q}\left[\frac{\widetilde{D}_{1}(\Delta)}{\widetilde{D}_{1}^{\prime}(\Delta)}\right]$. Now, we have from 
(3) that $\frac{d \Delta}{d Q}=\frac{1}{1-g^{\prime}(\Delta)}$, with $g^{\prime}(\Delta)=\frac{-2\left(\widetilde{D}_{1}^{\prime}(\Delta)\right)^{2}-\widetilde{D}_{1}^{\prime \prime}(\Delta)\left(1-2\left(\widetilde{D}_{1}(\Delta)\right)\right)}{\left(\widetilde{D}_{1}^{\prime}(\Delta)\right)^{2}}$, so that

$$
\begin{aligned}
\frac{\partial}{\partial Q}\left[\frac{\widetilde{D}_{1}(\Delta)}{\widetilde{D}_{1}^{\prime}(\Delta)}\right] & =\frac{\left(\widetilde{D}_{1}^{\prime}(\Delta)\right)^{2}-\widetilde{D}_{1}^{\prime \prime}(\Delta) \widetilde{D}_{1}(\Delta)}{\left(\widetilde{D}_{1}^{\prime}(\Delta)\right)^{2}} \frac{\left(\widetilde{D}_{1}^{\prime}(\Delta)\right)^{2}}{3\left(\widetilde{D}_{1}^{\prime}(\Delta)\right)^{2}+\widetilde{D}_{1}^{\prime \prime}(\Delta)\left(1-2\left(\widetilde{D}_{1}(\Delta)\right)\right)} \\
& =\frac{\Omega(\Delta)-1}{3 \Omega(\Delta)+\frac{\left(1-2\left(\widetilde{D}_{1}(\Delta)\right)\right)}{\widetilde{D}_{1}(\Delta)}},
\end{aligned}
$$

where $\Omega(\Delta) \equiv \frac{\left(\widetilde{D}_{1}^{\prime}(\Delta)\right)^{2}}{\widetilde{D}_{1}^{\prime \prime}(\Delta) \widetilde{D}_{1}(\Delta)}$. As $\Delta$ tends to $b$, we want to show that the Left-Hand Side approaches some number below 1 . Now, $\widetilde{D}_{1}(\Delta)$ tends to 1 as $\Delta$ approaches $b$, and $\Omega(\Delta)$ is negative (since $\widetilde{D}_{1}^{\prime \prime}(\Delta)<0$ for $\Delta$ close enough to $b$ ), which proves the result.

Finally, Firm 0 earns zero under one-sided information for high enough $Q$ (since it has no market), but it always earns positive profits under full information.

What this means is that the quality advantaged firm may want to hold back information and keep consumers uniformed. Nevertheless, the other firm's incentives lie in the opposite direction. Comparative advertising can permit this firm to reach its preferred information state.

\section{$5 \quad$ Equilibrium information disclosure}

We can now address the equilibrium advertising strategies starting with the case when comparative and negative advertising are debarred. Firms are viewed as setting advertising content before the price sub-game is resolved, so there is a two-stage game in ad content and then pricing. In the context of consumers going to the store for a pain reliever, they see all ads before going, and they see all prices on arrival. If they have no information about a product's attributes, they use the expected match value of zero. Otherwise, they know the match value communicated from any ads. Recall that advertising is costless. 
Proposition 6 Suppose that $Q>0$ is small enough. Then with comparative advertising debarred, the only equilibrium involves each firm revealing its match. This is still an equilibrium when comparative advertising is allowable.

Proof. For $Q=0$, for any distribution apart from the uniform, from Proposition 3, each firm's profit is strictly higher when it reveals information than when it does not, regardless of the strategy of the other firm. By continuity, this property still holds for $Q>0$ small enough, hence the equilibrium stated is unique. For the uniform, the analysis in the Appendix shows both firms strictly better off revealing than not (see also the diagrams in the section below). Both revealing own matches is still an equilibrium when the comparative advertising is allowed since all information is revealed by the firms separately, and so there is no extra information to be revealed.

The uniqueness of equilibrium with comparative advertising debarred also holds for $Q=0$ except for the uniform density. The uniform admits other equilibria since firms are indifferent between one-sided and full information (see Proposition 3). In particular, either one alone revealing is also an equilibrium.

Corollary 3 The optimal revelation is implemented in equilibrium for $Q$ close enough to 0.

Proof. In equilibrium, all information is revealed. This is optimal, given firm pricing, because in the neighborhood of $Q=0$ prices are arbitrarily close so that the consumer allocation is arbitrarily close to optimal. This indeed ensures the full social optimum is arbitrarily close to being attained.

In this case there is no special role for comparative advertising and also no role for expanding (or restricting) advertising. Matters are different for high $Q$.

Proposition 7 Suppose that $Q$ is large enough and $f(b)>0$. Then with comparative advertising debarred, equilibrium involves neither firm revealing its match. 
Proof. From Propositions 4 and 5, Firm 1's profit is higher when it does not reveal its match information than when it does, regardless of the strategy of Firm 0 (note that if Firm 0 does not reveal, Firm 1 is better off not revealing because it serves the entire market in both cases and price is higher when not revealing since it does not need to get on board the consumer most disliking it). Given Firm 1 does not reveal, Firm 0 gets zero profits regardless; by the advertising tie-breaking rule, it will not reveal.

Note that Firm 0's incentive not to disclose any information is weak: it is indifferent between revealing and not revealing because in any case it is kept out of the market. The possibility of resorting to comparative advertising changes the situation quite strikingly.

Proposition 8 Suppose that $Q$ is large enough and $f(b)>0$. Then with comparative advertising allowed, the only equilibrium involves comparative advertising by Firm 0, which reveals all information of both products.

Proof. Each firm revealing only its own information is not an equilibrium because Firm 1 would prefer not to reveal. If Firm 1 does not reveal, then Firm 0 reveals all information, by Proposition 4. Firm 1 then reveals nothing (by the tie breaking rule). If Firm 0 revealed only its own information, Firm 1 would reveal nothing, but then Firm 0 would use comparative advertising, which is therefore an equilibrium. it remains to consider negative advertising. Both will not use it because then Firm 1 would withdraw (preferring one-sided to full information). Firm 0 will not use it alone because it prefers full information, and hence comparative advertising. Firm 1 will not use it alone because Firm 0 would also then use it (whereupon Firm 1 would withdraw).

Corollary 4 Welfare is lower when comparative advertising is allowed for $Q$ large enough and $f(b)>0$.

Proof. This result follows from Proposition 8 because welfare is lower under full information than for one-sided information for $Q$ large enough. To see that welfare is lower, it 
suffices to note that the welfare optimum stipulates that all consumers should be allocated to Firm 1 if its quality advantage exceeds the maximum difference in match values, i.e., $Q \geq 2 b$, which must hold for $Q$ large enough.

Comparative advertising leads to full information revelation, and this is harmful to welfare. This is not because full information yields higher prices. Indeed, with quality asymmetries, prices can be higher under one-sided information than full information, as seen for the uniform example below. This means that consumers may nonetheless be better off with comparative advertising. Furthermore, in this model, high prices are not intrinsically harmful since there is no deadweight loss from non-purchase. It is not even the case that prices are more distorted (in the sense of being more different for given $Q$ ) under full information than one-sided or no information. It is the interaction of the distortion with the information structure that causes the welfare loss: from Proposition 2, one-sided information distorts the allocation of consumers in favor of the high quality product and this outweighs the adverse impact of equilibrium pricing that favors the low quality product whereas under full information, price distortion is not is the only source of inefficiency.

The full range of outcomes for the uniform density is illustrated next.

\subsection{Equilibrium profits and equilibrium information disclosure; uniform density}

We give a full characterization of sub-game outcomes and the full equilibrium for the special case of uniform density on $\left[-\frac{1}{2}, \frac{1}{2}\right]$ in the Appendix.

We2 first compare firm pricing behavior under one-sided information disclosure with that under full information. Assume first that $Q<3 / 2$ so that Firm 0 retains some positive market share in the one-sided equilibrium. ${ }^{9}$

From the general pricing formula (3), Firm 1's equilibrium net quality advantage $\Delta$ solves

\footnotetext{
${ }^{9}$ This bound comes from applying Proposition 1, Case $1: \Delta_{u}+\frac{1}{D_{1}^{\prime}\left(\Delta_{u}\right)}$ for the uniform is equa1 to $\frac{1}{2}+1$.
} 
$Q=\Delta-g(\Delta)$. The function $g$ is defined by $(2)$ as $g(\Delta)=\frac{1-2 D_{1}}{D_{1}^{\prime}}$, so that

$$
\bar{g}(\Delta)=-2 \Delta
$$

for one-sided information transmission (recalling $\bar{D}_{1}(\Delta)=F(\Delta)=\frac{1}{2}+\Delta$ ) and

$$
\tilde{g}(\Delta)=-\Delta-\frac{\Delta}{1-\Delta}
$$

for full information (recalling $\widetilde{D}_{1}(\Delta)=\int_{-b}^{b} F(r+\Delta) f(r) d r$ which is $\frac{1+2 \Delta-\Delta^{2}}{2}$ for $\Delta \geq 0$ ). It is readily verified that both $\bar{g}$ and $\tilde{g}$ are strictly decreasing, and, furthermore, $\bar{g}>\tilde{g}$ for the relevant range of $\Delta \in(0,1)$. These properties establish:

Lemma 6 For the uniform density and $Q \leq 3 / 2$, price differences satisfy $\widetilde{\Delta}<\bar{\Delta}$.

This means that the extra product differentiation involved with full information revelation exacerbates price differences. Nonetheless, they still are less than the quality difference, as per Lemma 1.

From the first-order conditions under the two different information structures, Firm 0's prices satisfy (see the Appendix):

$$
\bar{p}_{0}=\frac{1}{2}-\bar{\Delta}
$$

under one-sided information and

$$
\widetilde{p}_{0}=\frac{1-\widetilde{\Delta}}{2}
$$

under full information disclosure, where $\bar{\Delta}$ and $\widetilde{\Delta}$ are the corresponding equilibrium $\Delta$ 's.

Lemma 7 For the uniform density and $Q \leq 3 / 2$, prices satisfy $\widetilde{p}_{0}>\bar{p}_{0}$ and $\widetilde{p}_{1}>\bar{p}_{1}$.

Proof. From the two price expressions given above, it is clear that $\widetilde{p}_{0}>\bar{p}_{0}$ (for given $\Delta>0)$. Furthermore, the two price expressions are decreasing in $\Delta$ and since Lemma 6 shows in equilibrium, $\widetilde{\Delta}<\bar{\Delta}$, we must have $\widetilde{p}_{0}>\bar{p}_{0}$ in equilibrium. Finally, in order for $\widetilde{\Delta}<\bar{\Delta}$ we must also have $\widetilde{p}_{1}>\bar{p}_{1}$ in equilibrium. 
Thus, for $Q \leq \frac{3}{2}$, both firms charge higher prices when consumers know both products than when they know only one. ${ }^{10}$ The above results may be used along with Proposition 2 to establish that the low quality Firm 0 is better off if both products are known.

Lemma 8 For the uniform density, profits satisfy $\widetilde{\pi}_{0}>\bar{\pi}_{0}$.

Proof. Both demands for Firm 0 (with one-sided or full information) are decreasing in $\Delta$ and, by Proposition 2, demand with full information is strictly larger for a given $\Delta>0$. Since, by Lemma 6, Firm 1's net quality advantage, $\Delta$, is lower under full information, demand for Firm 0 is larger with full information. Furthermore, since it charges a higher price, it earns a higher profit.

The converse to the argument in the proof above is that demand for the high quality firm is lower with full information than when only one product is known. Since it charges a higher price, with full information, equilibrium profits for the high quality firm may not be compared on the basis of the above results. We show below that the high quality firm also prefers full information if $Q$ is not too large but prefers one-sided information for $Q$ large enough.

Lemma 9 For the uniform density, there exists a quality value $\hat{Q}>3 / 2$ such that profits satisfy $\widetilde{\pi}_{1}>\bar{\pi}_{1}$ for $0<Q<\hat{Q}$ and $\widetilde{\pi}_{1}<\bar{\pi}_{1}$ for $Q>\hat{Q}$.

Proof. These properties are found by direct calculation given the values given in the Appendix for prices in the various regimes.

Note that the large quality difference result is consistent with Proposition 5 . The uniform is rather special because profits are equal under one-sided and full information when $Q=0$. As $Q$ rises above zero, full information dominates one-sided information as regards Firm

\footnotetext{
${ }^{10}$ The result can easily be proved directly from the equilibrium prices given in the Appendix: $\bar{p}_{0}=\frac{1}{2}-\frac{Q}{3}$ and $\tilde{p}_{0}=\frac{(1-Q)+\sqrt{8+(1-Q)^{2}}}{8}$. The proof in Lemma 7 holds more generally.
} 
1's profits, and continues to do so whenever Firm 0's equilibrium demand under one-sided information is positive. Firm 1's profit indifference point happens for $\hat{Q}$ at which Firm 0 earns nothing under one-sided information. Hence for low $Q$ the results of Proposition 6 apply, and those of Propositions 7 and 8 for large $Q$ (above $\hat{Q}$ ). In the interim, some extra possibilities arise. These are discussed below.

The following Figures have $Q$ on the horizontal axis and profits on the vertical.

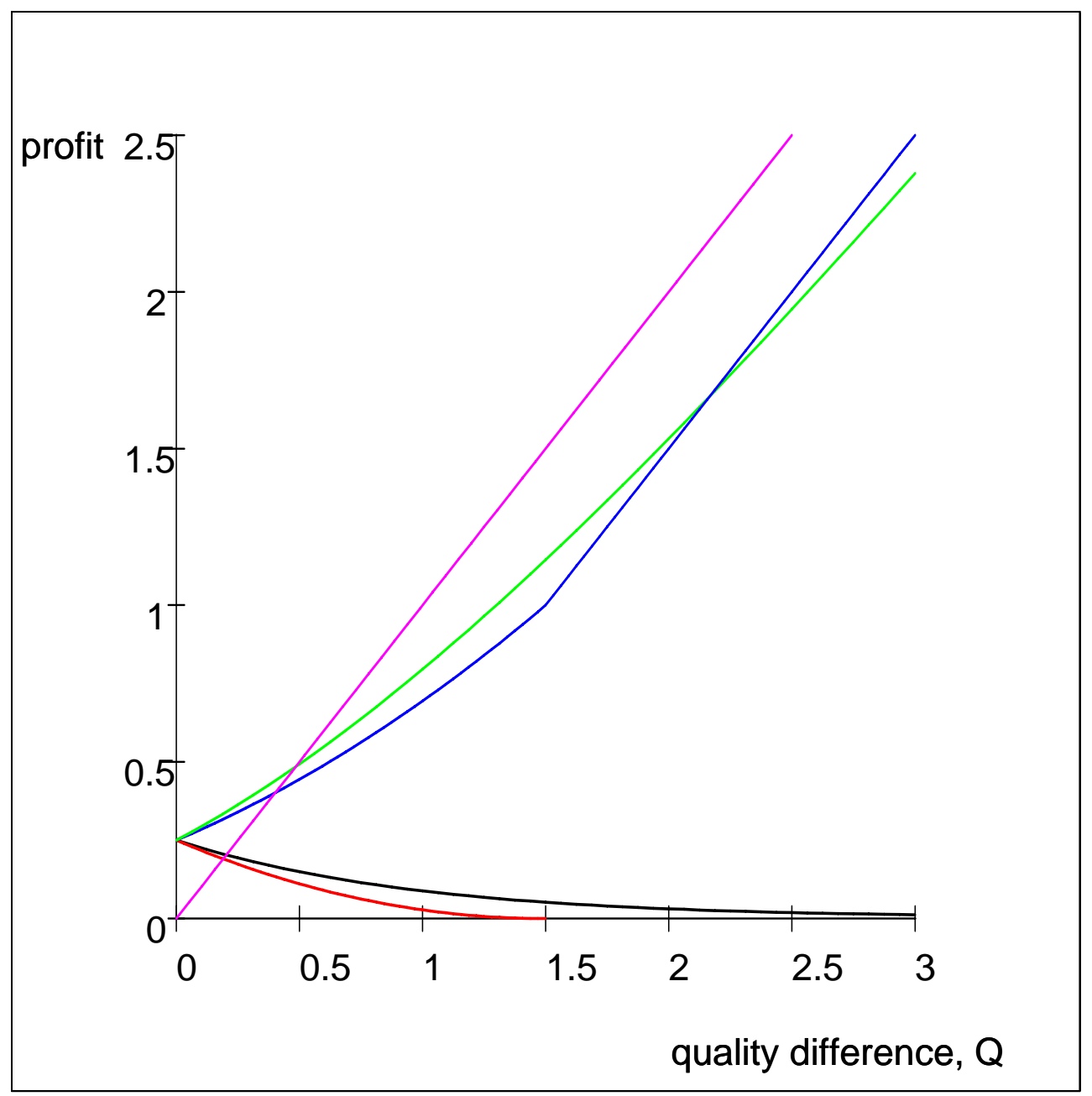

The upward-sloping lines are Firm 1's profits for no information (magenta), full information (green), and one-sided information (blue). While full information always dominates 
one-sided information for parameter values such that 0 serves some market, no information dominates both for a large quality advantage and loses to both for a small quality advantage. The downward-sloping lines are Firm 0's profits, with full information (black) always dominating one-sided information (red), which in turn always dominates no information (for $Q<3 / 2)$. The next Figure zooms in on the low $Q$ values.

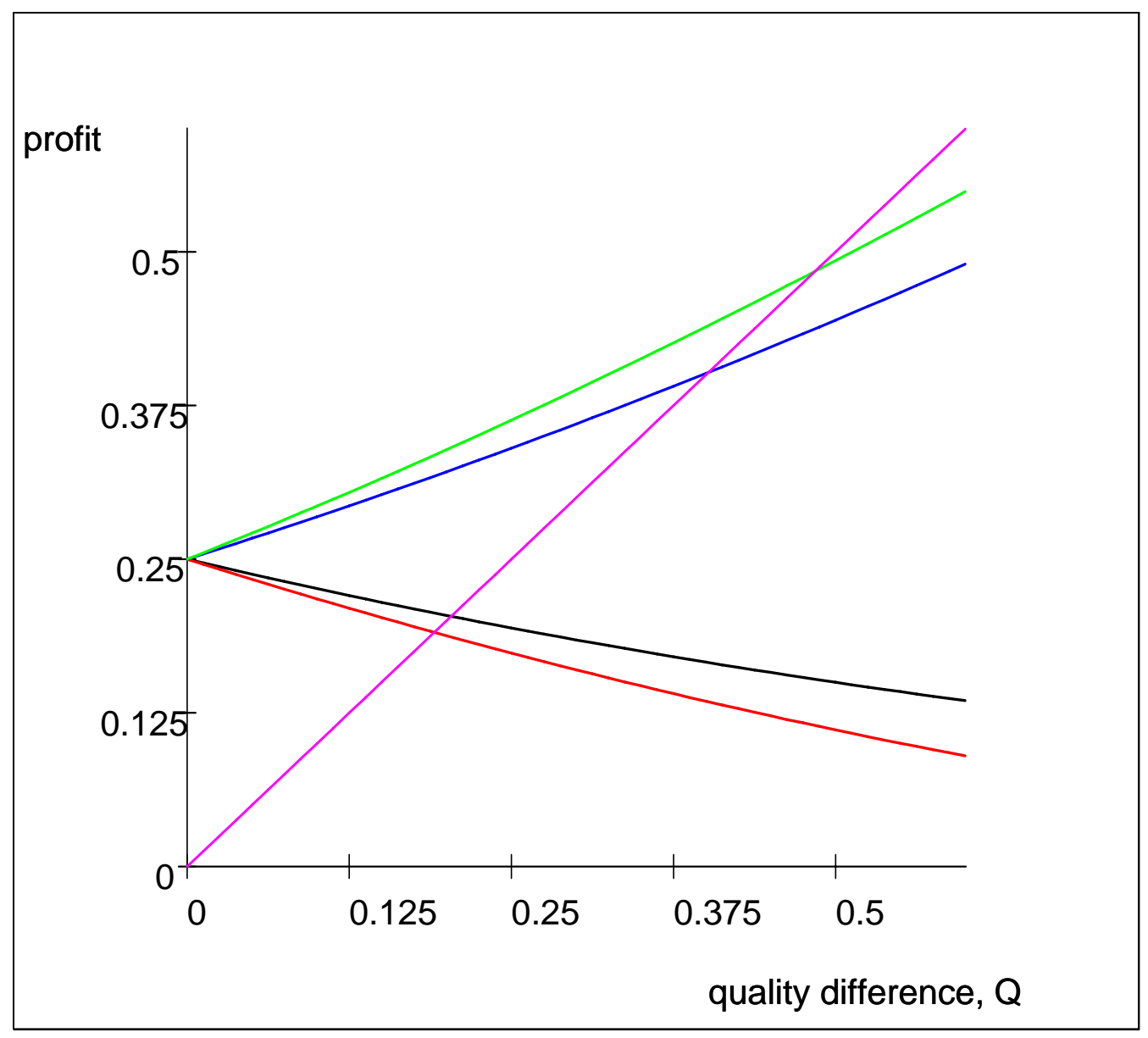

Equilibrium disclosure follows directly from these Figures. In particular, no information is never an equilibrium for $Q<3 / 2$ because Firm 0 can provide information, generate product differentiation and get a positive profit. Indeed, it is a dominant strategy (given equilibrium pricing in the sub-games) for 0 to provide information. Given that, Firm 1 will 
always want to provide information itself. So here there is full revelation, and no role for negative or comparative advertising insofar as any equilibrium still entails full revelation. ${ }^{11}$

Now consider $Q>3 / 2$. The driver for the equilibrium is what happens to Firm 1 's profit between full information and one-sided information. ${ }^{12}$ As per Lemma 9, this depends on which side of $\hat{Q}$ the quality difference $Q$ lies. For $Q>\hat{Q}$ (which exceeds $3 / 2$ ), the only equilibrium is for there to be no advertising if comparative advertising is not permissible (as per Proposition 7): it is a dominant strategy (among the pricing sub-games) for 1 to NOT reveal, and, in response, since 0 gets nothing either way, it does not reveal either (by the tie-break rule that favors less information over more in case of indifference). Otherwise, the only equilibrium is comparative advertising by Firm 0 (as per Proposition 8), which enables it to survive.

For $Q \in[3 / 2, \hat{Q}]$, equilibrium is driven by the twin properties that $\bar{\pi}_{1}<\widetilde{\pi}_{1}<\pi_{1}^{z e r o}$ and $\tilde{\pi}_{0}>\bar{\pi}_{0}=\pi_{0}^{z e r o}(=0)$. With comparative advertising debarred, one equilibrium has no information provided, and another has both providing own match information. In the former case, Firm 1 prefers no information to one-sided information and so does not advertise if Firm 0 does not advertise, and Firm 0 will not advertise if Firm 1 does not. In the other equilibrium, each firm prefers to advertise if the other advertises. Allowing now comparative advertising, the latter is still an equilibrium, as is reciprocal negative advertising by the same token. The former is not because Firm 0 would prefer comparative advertising, and this comparative advertising is the other equilibrium. ${ }^{13}$ However, since $Q>1$, comparative

\footnotetext{
${ }^{11}$ With comparative advertising allowed, there is an equilibrium with each providing information about matches with its rival ("negative advertising"). There is another equilibrium with either of the firms providing a full comparison and the other doing nothing.

${ }^{12}$ The one-sided information price, given the rival sets $p_{0}=0$ and that Firm 1 serves the whole market, must ensure that 1 gets on board the consumer who least likes it, which is $r_{0}=-\frac{1}{2}$; this means a price of $Q-1 / 2$ (since 1 delivers expected utility zero to all). Of course, this is less attractive than no information, whereby the price charged is $Q$ (with no product differentiation, the keel is even).

${ }^{13}$ Equilibrium strategies cannot involve Firm 1 giving a full comparison and 0 doing nothing, since 1 would deviate to advertising nothing at all. Nor can they involve negative advertising by either alone: both prefer full information to one-sided information, which outcome they can get by either full comparative advertising or indeed reciprocal neagative advertising.
} 
advertising allows a weak firm to survive against the optimality rule. ${ }^{14}$

Finally, note that (using the price expressions in the Appendix) as $Q$ becomes large, the full information price for Firm 1 goes to $Q-1$, whereas its one-sided information price is $Q-\frac{1}{2}$. This shows that the full information price can be lower for the high quality firm. Moreover, consumer surplus is higher under full information. Under one-sided information all consumers buy from Firm 1, whereas under full information those who still buy from Firm 1 pay a lower price and those choose to buy from Firm 0 are better off.

\section{Discussion}

It was assumed above that the good advertised is an experience good, and that qualities are known to consumers beforehand. We first show that the results hold too when the good is a search good as long as search costs are high enough. We then show that if qualities are known to firms but not consumers, and firms can advertise quality information, then firms will advertise qualities, so the basic set-up still holds.

\subsection{A search good}

Suppose that a consumer can observe the product's attributes before making a purchase at $\operatorname{cost} c>b$. She must incur the visit $\operatorname{cost} c$ to buy from either firm, but the cost of the first visit is irrelevant since the consumer must buy one of the two products in any case. We now show that demands are exactly the same as with the experience good version of the model (and so prices and equilibria are too). This we do by showing that the consumer always buys from the first firm she visits so that the information she obtains when she gets there is irrelevant.

Consider a consumer who, after observing prices and advertised information, decides to

\footnotetext{
${ }^{14}$ Comparative ads more generally might facilitate toe-hold entry for entrants to become larger later, and this could be desirable in an extended context.
} 
visit Firm $i$ first. If information about product $i$ was provided through advertising, then the consumer has not learned anything from her first visit and she will clearly choose to buy product $i$ given that she initially chose to visit Firm $i$. Let us thus assume that $r_{i}$ was unknown to her when she chose to visit Firm $i$. A first possibility is that she was informed about her match with the other product when she made that choice. A standard sequential search argument shows that she would then have chosen to incur search cost $c$ to find out about $r_{i}$, if and only if her match with the competing product $\left(r_{j}, j \neq i\right)$ augmented by the price difference $p_{i}-p_{j}-c$ is strictly less than $-c<-b .{ }^{15}$ She will then choose to purchase product $i$ even if she finds out that $r_{i}=-b$. Suppose finally that neither product was known when the consumer decided on her first visit. Since she chose to visit Firm $i$ first, we must have $p_{i} \leq p_{j}$. Then the search theoretic argument used above shows that, when she finds out her match with product $i$, for any $r_{i}$, she will not visit Firm $j$ : since $r_{i}+p_{j}-p_{i} \geq-b>-c$ it is not worth incurring search cost $c$ to find out about $r_{j} .{ }^{16}$ The ability of the consumer to obtain product information which has not been advertised before buying therefore has no impact on her choice of product since it would be too costly to use that information.

In an earlier version of this paper, we studied product information disclosure with a search good. Assuming that only one of the two products is unknown, we found that the firm selling the unknown product would disclose horizontal attributes if and only if its quality is below the other product's. Furthermore, a known product with low quality uses comparative advertising (if allowed) to disclose information about an unknown high quality product. ${ }^{17}$ Hence the predictions of the model with search (and only one product unknown), are qualitatively similar to those derived in the present paper.

\footnotetext{
${ }^{15}$ Here $p_{j}+c$ is the price of the known product $j$.

${ }^{16}$ Here the price of the known product is $p_{i}$ since the cost of visiting Firm $i$ is already sunk. Furthermore, the exact condition used here assumes that recalling Firm $i$ 's offer after visiting Firm $j$ has no cost.

${ }^{17}$ These results hold as long as a pure strategy equilibrium exists, which is not necessarily the case for all search cost values or quality differences.
} 


\subsection{Quality disclosure}

Let us now consider the possibility that qualities as well as horizontal attributes are unknown. A standard result in the literature due to Milgrom (1981) and Grossman (1981), is that a monopoly firm that may disclose certifiable information about its product's quality, always discloses it in equilibrium. We now show that practically the same result holds for our duopoly setting with horizontal differentiation as well as vertical (quality). Assume that qualities for the two firms are independently drawn from the same distribution and that realizations are initially known only by firms. First note that no information disclosure is not an equilibrium. In such an equilibrium, firms would engage in symmetric Bertrand competition in the second stage and earn zero profit. It would be profitable for a firm to deviate and disclose its horizontal attributes thus creating some product differentiation. Second, there is no equilibrium where only the low quality firm discloses its quality. Recall that, independent of what information is revealed about horizontal attributes, the high quality firm earns some strictly positive profit that is strictly increasing in its quality. Suppose that for some given low quality and horizontal attributes information disclosed, there is some non-zero subset of high qualities that are not disclosed in equilibrium. The consumers form some conditional expectation as to the quality of a firm that does not disclose so that any firm with a quality above that conditional expectation is better off disclosing its quality.

Now consider the choice of a low quality firm. With no horizontal attributes disclosed or if only one product's attributes are disclosed and the quality difference is large enough, it earns zero profits. Otherwise, its profit is strictly positive and strictly increasing in its quality (Corollary 2). Whenever the latter situation arises, then an argument analogous to that used for the high quality firm shows that the low quality is always revealed. The only situation when the low quality firm cannot guarantee itself some strictly positive profit is when the quality difference is very large and comparative advertising is not allowed. Then, 
the low quality is not disclosed but consumers update their beliefs accordingly and anticipate the low quality is very low relative to the high quality. The only information disclosed in that case is the higher quality and the high quality firm serves the whole market.

To summarize, the only situation where the market outcome would not be fully identical to that obtained while assuming that qualities are known is when the quality difference is large and comparative advertising is not allowed. Then the low quality is not revealed but it is anticipated by consumers to be much lower than the high quality. The market outcome is qualitatively similar to that derived in previous sections where the quality difference should be replaced by the difference between the high quality and some expected low quality.

\section{Conclusions}

Comparative advertising involves informing consumers of characteristics of rival products. On the surface, the practice would appear socially beneficial (assuming of course that the advertising is not misleading) and should lead to better informed choices. It has though been pointed out that it may relax price competition (and lead to higher prices) because it increases product differentiation. However, this is also true for direct advertising, so a useful theory should also explain when it is used and not.

The theory proposed here does this by focussing on intrinsic quality differences in the products sold. If these qualities are quite similar, firms have enough incentive to advertise their own products and comparative advertising plays no role. This is true in a balanced market with firms that have similar market shares. Only if product qualities or marginal production costs are sufficiently different does the ability to use comparative advertising come into play. If it is illegal, the dominant product can serve the market without needing to advertise, and the minor product may be overwhelmed. If comparative advertising is legal though, the minor product can improve its consumer base and survive by using advertising 
that targets the dominant product and compares characteristics. Thus, the model predicts that comparative advertising is used by weaker firms targeting market leaders. There is some empirical support for the contention that the market leader does not engage in comparative advertising, but those just behind it do. Tylenol has $25 \%$ of the market for over-the-counter pain relievers, and does no comparative advertising regarding the other OTC medicines. Advil, in second place with $15 \%$ of the market, spends over half (58\%) of its advertising budget on comparative ads, mainly about Tylenol.

The model also delivers a salutary message for comparative advertising. It enables weaker firms to survive through an equilibrium pricing distortion whereby the stronger firm overprices its product. The dominant firm effectively parlays its quality advantage into both a high mark-up and high sales. The paper shows that this distortion can be sufficiently acute that it overwhelms the informational benefits of comparative advertising. However, some caveats are worth drawing. First, even when total welfare falls, it may be that consumer welfare rises since comparative advertising (full information) may be associated with lower prices when quality (or cost) differences are large enough. Second, such lower prices might entail a lower deadweight loss if the model were extended to allow for non-purchase options.

The modeling approach is based on truthful informative advertising of horizontal characteristics with rational consumers. The approach was chosen to portray comparative advertising in a favorable light by allowing the conveyance of more hard information. If consumers were not rational (rationality is embodied in the model in the assumption that consumers form correct expectations of mean valuations in the absence of information), they might be manipulated by misleading advertising. The legal system may play an important role in ensuring truthfulness in this context.

We have also assumed that firms only are able to convey full information or else none at all. Partial information (in a monopoly context) is addressed in Anderson and Renault (2006). The information portrayed here was assumed to be perfectly certifiable at no cost. 
An approach to be investigated in future research is to allow for imperfect certification (see Shin, 1994) and/or costly certification. Finally, advertising has been assumed to reach all consumers costlessly. Introducing costly reach would be another worthwhile extension to the model.

\section{References}

[1] Aluf, Yana, and Oz Shy (2001) Comparison advertising and competition. Mimeo, University of Haifa.

[2] Anderson, Simon P. and André de Palma (1988): Spatial Price Discrimination with Heterogeneous Products. Review of Economic Studies, 55, 573592.

[3] Anderson, Simon P. and André de Palma (2001): Product Diversity in Asymmetric Oligopoly: Is the Quality of Consumer Goods Too Low? Journal of Industrial Economics, 49, 113-135.

[4] Anderson, Simon P. and Renault, Régis (1999): Pricing, Product Diversity and Search Costs: a Bertrand-Chamberlin-Diamond Model. RAND Journal of Economics, 30, 719735 .

[5] Anderson, Simon P. and Renault, Régis (2000): Consumer Information and Firm Pricing: Negative Externalities from Improved Information. International Economic Review, $31,721-741$.

[6] Anderson, Simon P. and Renault, Régis (2006): Advertising content. American Economic Review, 96, 93-113.

[7] Bagwell, Kyle (2006): The Economic Analysis of Advertising. Mimeo, Columbia University. 
[8] Barigozzi, Francesca, Paolo Garella, and Martin Peitz (2006): With a little help from my enemy: comparative vs. generic advertising. Mimeo, University of Bologna.

[9] Barigozzi, Francesca and Martin Peitz (2005): Comparative advertising and competition policy. Forthcoming in Recent Developments in Antitrust Analysis, edited by Jay Pil Choi, MIT Press.

[10] Butters, Gerard R. (1977): Equilibrium Distributions of Sales and Advertising Prices. Review of Economic Studies, 44, 465-491.

[11] Donthu, Naveen (1998): A cross-country investigation of and attitude toward comparative advertising. Journal of Advertising, 27, 111-133.

[12] Grewal, Dhruv, Sukumar Kavanoor, Edward F. Fern, Carolyn Costley, and James Barnes (1997): Comparative versus noncomparative advertising: a meta-analysis. Journal of Marketing, 61, 1-15.

[13] Grossman, Gene M. and Shapiro, Carl (1984): Informative Advertising and Differentiated Products. Review of Economic Studies, 51, 63-81.

[14] Grossman, Sanford J. (1981): The informational role of warranties and private disclosure about product quality. Journal of Law and Economics 24(3), 461-83.

[15] Liaukonyte, Jura (2006): Is comparative advertising an active ingredient in the market for pain relief? Mimeo, University of Virginia.

[16] Meurer, Michael J., and Stahl, Dale O., II (1994): Informative Advertising and Product Match. International Journal of Industrial Organization, 12, 1-19.

[17] Milgrom, Paul R. (1981): Good news, bad news: representation theorems and applications. Bell Journal of Economics, 12, 380-391. 
[18] Nelson, Phillip J. (1974): Advertising as information. Journal of Political Economy. 82, 729-754.

[19] Shin, Hyun (1994): The Burden of Proof in a Game of Persuasion. Journal of Economic Theory, 64, 253-263.

[20] Thompson, Debora Viana and Rebecca W. Hamilton (2006): The effects of information processing mode on consumers' responses to comparative advertising. Journal of Consumer Research, 32, 530-540.

[21] Wolinsky, Asher (1986): True Monopolistic Competition as a Result of Imperfect Information. Quarterly Journal of Economics, 101, 493-511. 


\section{Appendix}

\section{Proofs from Section 2}

\subsection{Lemma 1}

Assume that $Q \geq 0$. We first show that $\Delta=Q$ or $\Delta=0$ imply that $Q=0$. Assume first that $\Delta=Q$, so that $p_{0}=p_{1}=p$. Then, in order for Firm 0 not to wish to deviate, for any real number $\delta \geq-p$ we must have

$$
p\left[1-D_{1}(Q)\right] \geq(p+\delta)\left[1-D_{1}(Q+\delta)\right]
$$

which is equivalent to

$$
(p-\delta) D_{1}(Q+\delta) \geq p D_{1}(Q)+\delta\left[1-2 D_{1}(Q+\delta)\right]
$$

If $Q>0$, then for any $\delta \in(-Q, 0], D_{1}(Q+\delta)>\frac{1}{2}$ and thus $\delta\left[1-2 D_{1}(Q+\delta)\right]>0$. Then Firm 1 could deviate from $p$ to $p-\delta$ so as to earn a profit of $(p-\delta) D_{1}(Q+\delta)$ which strictly exceeds $p D_{1}(q)$. So we must have $Q=0$ in order for $\Delta$ to be equal to $Q$ in equilibrium.

Now suppose that $\Delta=0$ so that $p_{0}=p_{1}-Q$. Then, for any $\delta>0$ we must have

$$
\frac{1}{2}\left(p_{1}-Q\right) \geq\left(p_{1}-Q+\delta\right)\left[1-D_{1}(\delta)\right]
$$

or, equivalently,

$$
\left(p_{1}-\delta\right) D_{1}(\delta) \geq \frac{1}{2} p_{1}+\left(\delta-\frac{Q}{2}\right)\left[1-2 D_{1}(\delta)\right]
$$

If $Q>0$, since $\delta>0$ so that $D_{1}(\delta)>\frac{1}{2}$, for $\delta$ sufficiently small, the right hand side strictly exceeds $\frac{1}{2} p_{1}$. Firm 1 would therefore be better off charging $p_{1}-\delta$ rather than $p_{1}$. Thus in order for $\Delta$ to be zero in equilibrium we must have $Q=0$.

We now show that in equilibrium $0 \leq \Delta \leq Q$ which, along with the results above, proves the Lemma for $Q \geq 0$. First, it is necessary that Firm $i$ prefers $p_{i}$ to its rival's price so that

$$
p_{0}\left[1-D_{1}(\Delta)\right] \geq p_{1}\left[1-D_{1}(Q)\right]
$$


and

$$
p_{1} D_{1}(\Delta) \geq p_{0} D_{1}(Q)
$$

Adding these two inequalities and rearranging yields

$$
p_{0}-p_{1} \geq\left(p_{0}-p_{1}\right)\left[D_{1}(Q)+D_{1}(\Delta)\right]
$$

Since $Q \geq 0$, if $p_{0}>p_{1}$, then $D_{1}(\Delta)>D_{1}(Q) \geq \frac{1}{2}$. Thus $D_{1}(Q)+D_{1}(\Delta)>1$ which contradicts inequality (9). So we must have $p_{0} \leq p_{1}$, or equivalently $\Delta \leq Q$.

It must also be the case that Firm $i$ prefers charging $p_{i}$ than a price that would set $\Delta$ to zero, so that

$$
p_{0}\left[1-D_{1}(\Delta)\right] \geq \frac{1}{2}\left(p_{1}-Q\right)
$$

and

$$
p_{1} D_{1}(\Delta) \geq \frac{1}{2}\left(p_{0}+Q\right) .
$$

Adding these two inequalities yields

$$
\left[1-D_{1}(\Delta)\right] p_{0}+D_{1}(\Delta) p_{1} \geq \frac{1}{2}\left(p_{0}+p_{1}\right)
$$

We know from above that $p_{1} \geq p_{0}$. If $p_{1}>p_{0}$, inequality (10) requires that $D_{1}(\Delta) \geq \frac{1}{2}$ and therefore $\Delta \geq 0$. If $p_{1}=p_{0}$ then $\Delta=Q \geq 0$. This completes the proof for $Q \geq 0$.

Similar arguments establish the result for $Q \leq 0$. Q.E.D.

\subsection{Lemma 2}

If $\Delta<\Delta_{\ell}$ or $\Delta>\Delta_{u}$, then whichever firm has a demand of 1 could increase its price without losing any demand and thus, increase it profit; this proves the first part of the Lemma.

We now show that differentiability at $\Delta_{k}$ implies that $\Delta=\Delta_{k}$ cannot be an equilibrium. For instance for $k=u$, differentiability at $\Delta_{u}$ implies that the left derivative of $D_{1}$ at $\Delta_{u}$ is 0 (since the right derivative is zero). Then Firm 1's profit derivative is $D_{1}\left(\Delta_{u}\right)=1>0$ so that Firm 1 would deviate and increase its price. Similarly, if $\Delta=\Delta_{\ell}$, Firm 0 would wish to increase its price from the candidate equilibrium. Q.E.D. 


\subsection{Proposition 1}

The argument for existence is standard (see Caplin and Nalebuff, 1991).

Before going through the 3 cases it is useful to note that since $D_{1}$ and $D_{0}=1-D_{1}$ are strictly log-concave, $g$ is strictly decreasing on $\left[\Delta_{\ell}, \Delta_{u}\right]$ and so the right-hand side of equation (3) (the equation is $Q=\Delta-g(\Delta)$ ) is strictly increasing on that same interval. This shows that $\Delta$ is uniquely defined in Case 1 . Furthermore, because $\frac{D_{i}^{\prime}}{D_{i}}, i=0,1$ is strictly increasing, prices are uniquely determined by equation (1). It also shows that in this case $\Delta$ must be strictly increasing in $Q$. Implicit differentiation of (3) and Assumption 2 imply $\frac{d \Delta}{d Q}<1$.

First consider case 3. If $\Delta \leq \Delta_{\ell}$, then Firm 1 makes zero profit whereas, since $Q>0$. it could obtain a strictly positive profit by charging, for instance, a price $p_{0}+Q>0$. Next note that $\Delta_{u}+\frac{1}{D_{1}^{\prime}\left(\Delta_{u}\right)}$ is the right-hand side of (3) evaluated at $\Delta=\Delta_{u}$. Since $Q$ is at least as large and the right-hand side of (3) is strictly increasing on $\left(\Delta_{\ell}, \Delta_{u}\right)$, there is no $\Delta$ in that interval that satisfies (3). Since an equilibrium exists and using Lemma 2, we must have $\Delta=\Delta_{u}$. We also know from Lemma 2 that this case may arise only if $D_{1}^{\prime}\left(\Delta_{u}\right)>0$ so that Firm 0's profit left derivative with respect to $p_{0}$ is $-p_{0} D_{1}^{\prime}\left(\Delta_{u}\right)$ which would be negative if $p_{0}>0$ and thus Firm 0 would wish to decrease its price. Thus we have $p_{0}=0$ and the expression for $p_{1}$ follows.

Case 2 may be treated with symmetric arguments.

Now consider case 1 . We show that we may not have $\Delta=\Delta_{u}$ and a symmetric argument would show that we cannot have $\Delta=\Delta_{\ell}$. From Lemma 2, this suffices to complete the proof. Hence suppose that $\Delta=\Delta_{u}$. As was shown above, we must then have $p_{0}=0$. The right derivative of Firm 1's profit is given by $1-p_{1} D_{1}^{\prime}\left(\Delta_{u}\right)=1-\left(Q-\Delta_{u}\right) D_{1}^{\prime}\left(\Delta_{u}\right)$. Since

$Q<D_{1}\left(\Delta_{u}\right)+\frac{1}{D_{1}^{\prime}\left(\Delta_{u}\right)}$ the right derivative of profit strictly exceeds 0 . Then Firm 1 could increase its profit by increasing its price. Q.E.D. 


\subsection{Proposition 2}

From symmetry of $f$, equality clearly holds if $\Delta=0$. We now show that the inequality holds strictly for $\Delta>0$. Symmetry of $f$ implies

$$
\int_{-b}^{b} F(r+\Delta) f(r) d r=\int_{-b}^{0}[F(r+\Delta)+F(-r+\Delta)] f(r) d r,
$$

and

$$
F(\Delta)=\int_{-b}^{0} 2 F(\Delta) f(r) d r
$$

Hence it suffices to establish that $F(r+\Delta)+F(-r+\Delta)<2 F(\Delta)$ for all $r<0$. This is equivalent to

$$
F(-r+\Delta)-F(\Delta)<F(\Delta)-F(r+\Delta)
$$

or

$$
\int_{\Delta}^{-r+\Delta} f(s) d s<\int_{r+\Delta}^{\Delta} f(s) d s
$$

Using appropriate changes of variables, this condition may be rewritten as

$$
\int_{0}^{-r} f(\Delta+t) d t<\int_{0}^{-r} f(\Delta-t) d t .
$$

Since $\Delta>0$, quasi-concavity and symmetry of $f$ around zero implies that $f(\Delta+t)<f(\Delta-t)$, for all $t \in(0,-r]$. This ensures the proper inequality.

Symmetric arguments establish reverse inequalities for $\Delta<0$. Q.E.D.

\subsection{Pricing expressions for the uniform density}

We give a free-standing derivation of equilibrium prices for the uniform density $f(x)=1$ for $x \in\left[-\frac{1}{2}, \frac{1}{2}\right]$, and zero otherwise.

\subsection{One-sided information}

Since $\bar{D}_{1}(\Delta)=F(\Delta)$ in general, for the uniform density we have $\bar{D}_{1}(\Delta)=\frac{1}{2}+\Delta$ for $\Delta \in\left[-\frac{1}{2}, \frac{1}{2}\right]$ and $\bar{D}_{1}(\Delta)$ is zero below the lower bound and one above the upper bound. 
When within the bounds, $\bar{D}_{1}^{\prime}=-1$, so we have a simple linear demand system. ${ }^{18}$

We can immediately determine the equilibrium prices for $\Delta \in\left[-\frac{1}{2}, \frac{1}{2}\right]$ as

$$
p_{1}=\frac{1}{2}+\Delta \quad \text { and } \quad p_{0}=\frac{1}{2}-\Delta
$$

These prices depend only on net quality differences so we may apply Lemma 1.

Taking the difference of these two equations we can write out and solve for $\Delta=Q / 3$.

Substituting back gives prices as

$$
p_{0}=\frac{1}{2}-\frac{Q}{3}, \quad \text { and } \quad p_{1}=\frac{1}{2}+\frac{Q}{3}
$$

which therefore hold for the interior regime, with $\Delta=Q+p_{0}-p_{1}=Q / 3$ (which is consistent with Lemma 1): so that this regime applies when $Q<3 / 2$ (recall $Q>0$ ). Equilibrium profit levels are given by these prices squared (as is standard for linear demands with unit slopes).

Otherwise, for $Q \geq 3 / 2$, we have

$$
p_{0}=0 \quad \text { and } \quad p_{1}=Q-\frac{1}{2}
$$

Here the quality-advantaged firm prices so as to just retain the individual retaining the highest regard for Firm 0, which is the individual who has a match $r_{0}=1$, which compares to the mean value of 0 for Firm $1 .^{19}$

\subsection{Full information}

For the uniform density, recalling that $r_{1} \in\left[-\frac{1}{2}, \frac{1}{2}\right]$, (6) becomes

$$
\widetilde{D}_{1}(\Delta)=\int_{-1 / 2}^{1 / 2-\Delta}\left(\frac{1}{2}+r_{1}+\Delta\right) d r_{1}+\Delta=\frac{1+2 \Delta-\Delta^{2}}{2}
$$

\footnotetext{
${ }^{18}$ The "symmetric" version, with consumers knowing their valuations at both firms, does NOT give a linear demand system. This latter system is determined in the text below.

${ }^{19}$ Equivalently, as per Lemma 3, if Firm 1 reveals its match information while Firm 0 does not, 1 must price so that the consumer least enamoured of it (holding $r_{1}=0$ ) nonetheless buys against an expected value of 0 with Firm 0.
} 
Notice that $\Delta<1$ for both firms to have positive demands: for $\Delta>1$, Firm 1's demand is $\widetilde{D}_{1}(\Delta)=1$, but, by Lemma 1 , this is never relevant. ${ }^{20}$ Firm 0 's demand is $1-\widetilde{D}_{1}(\Delta)$ or:

$$
\widetilde{D}_{0}(\Delta)=\frac{(1-\Delta)^{2}}{2}
$$

Since evaluations for the two products are i.i.d. we have $\widetilde{D}_{1}(0)=\frac{1}{2}$, and all assumptions of Lemma 5 are satisfied. Thus the firm with the higher quality will set a higher net quality and thus garner a larger share of demand, even though it charges the higher price. ${ }^{21}$

We now find the equilibrium prices conditional on consumers knowing product specifications and qualities of both products (Perloff-Salop, uniform distribution, with asymmetric qualities, effectively). Since $\widetilde{D}_{0}(\Delta)=\frac{(1-\Delta)^{2}}{2}$, the first order condition for Firm 0 yields

$$
p_{0}=\frac{(1-\Delta)}{2} ;
$$

we can immediately substitute in for $\Delta=Q+p_{0}-p_{1}$ to yield a linear reaction function

$$
p_{0}=\frac{1-Q+p_{1}}{3} \text {. }
$$

For Firm 1, we have the first order condition $1-\frac{(1-\Delta)^{2}}{2}-p_{1}(1-\Delta)=0$.

Substituting in $p_{0}=\frac{(1-\Delta)}{2}$, then $1-2 p_{0}^{2}-2 p_{0} p_{1}=0$.

Solving out these equations for prices then gives the solutions as

$$
p_{0}=\frac{\hat{\omega}+\sqrt{8+\hat{\omega}^{2}}}{8}, \quad \text { and } \quad p_{1}=\frac{-5 \hat{\omega}+3 \sqrt{8+\hat{\omega}^{2}}}{8},
$$

where $\hat{\omega}=1-Q$. Note that these prices are equal at $\hat{\omega}=1$ (symmetry) to one half. They also verify $\Delta>0$, as desired.

\footnotetext{
${ }^{20}$ Demand is convex for $\Delta<0$ (high prices for Firm 1) and concave for $\Delta>0$ (low prices). The demand derivative is continuous on its support, and so there is no kink.

${ }^{21}$ Any best reply price for Firm 1 must satisfy $p_{1} \in\left[0, p_{0}+q_{1}-q_{0}-1\right]$, where the upper bound is where Firm 1's demand disappears. Hence Firm 1's profit is a continuous function that is defined over a compact set, and so has a maximum. Equilibrium existence follows from Caplin and Nalebuff (1991).
} 